\title{
ALBENDAZOLE RESISTANT DISSEMINATED CUTANEOUS CYSTICERCOSIS AND ASYMPTOMATIC NEUROCYSTICERCOSIS: A RARE OCCURRENCE
}

Prasad Dipak Andhare ${ }^{1}$

\section{HOW TO CITE THIS ARTICLE:}

Prasad Dipak Andhare. "Albendazole Resistant Disseminated Cutaneous Cysticercosis and Asymptomatic Neurocysticercosis: A Rare Occurrence". Journal of Evolution of Medical and Dental Sciences 2014; Vol. 3, Issue 13, March 31; Page: 3245-3249, DOI: 10.14260/jemds/2014/2275

ABSTRACT: Cysticercosis is a common parasitic infection in tropical countries. Many cases of disseminated cysticercosis are being reported recently. However DCC with asymptomatic neurocysticercosis is a rare occurrence. Still rarely reported cases are of albendazole resistant DCC and neurocysticercosis. We herein report a case of Albendazole resistant Disseminated Cutaneous Cysticercosis with simultaneous involvement of eyes, muscles and asymptomatic neurocysticercosis. Disease was resistant to albendazole. The patient responded to Praziquantel with near complete resolution of DCC and NCC.

KEYWORDS: Neurocysticercosis, DCC, NCC, Albendazole.

INTRODUCTION: Human cysticercosis is a zoonotic infection the result of accidental ingestion of eggs of Pork Tapeworm i.e. Taenia Solium, usually due to contamination of food by human feces with Taeniasis. Human cysticercosis is an important cause of epilepsy and neurological morbidity in many developing countries. Cysts occur especially in striated muscles, subcutaneous tissues, the nervous system and the eye. However less than 50 disseminated cysticercosis cases have been reported worldwide till date. ${ }^{1}$ Asymptomatic and incidental detection of neurocysticercosis is reported in to be $15 \%$ approximately. ${ }^{2}$ Neurocysticercosis, is clinically a pleomorphic disease that may be asymptomatic or manifest with mild to severe neurologic disease.

The clinical manifestations vary with the number of parasite, size, location of the lesion, stage of cysts and the intensity of the host's immune response. ${ }^{3}$ Cysticerci produce symptoms when the cysts begin to die. The inflammatory reaction produced due to their degeneration produce manifestations which include epilepsy, focal neurological signs, intracranial hypertension, cognitive decline, cerebellar ataxia, symptoms of hydrocephalus and psychiatric disorders.

About $54 \%$ of patients present with subcutaneous nodules. ${ }^{4}$ Del Brutto et al has proposed a set of diagnostic criteria based on neuroimaging studies, serological tests, clinical presentation and exposure history. ${ }^{5}$ CT and MRI remains the most effective means of diagnosis. Sensitivity of serological test tends to be high for patients with multiple cysts (94\%) but substantially lower for patients with a single cyst or calcified cysts (28\%). ${ }^{6}$ The management of cysticercosis with cysticidal drugs has been topic of debate. ${ }^{7}$ Albendazole and praziquantel which are currently available both are effective though Albendazole is 2-3 times more efficient than Praziquantel, ${ }^{8}$ also because of its low cost and availability it is used more widely. There is no role for cysticidal drugs in inactive neurocysticercosis, i.e. calcified cysts, since the parasites are dead.

In this report, simultaneous and extensive involvement of the brain, eyes, muscles and subcutaneous tissues and has been reported very few times previously in literature. Also resistance to albendazole and resolution following praziquantel is not yet reported. However they may only be partially effective against vesicular and colloidal shaped cysts. ${ }^{9}$ Although resistance of cysticercosis to 
Albendazole in humans has not been reported it may occur though. ${ }^{10}$ This is the report of a case of disseminated cysticercosis from Nagpur, Central India.

CASE REPORT: 36 yr. old man, laundry man by occupation, came with complaints of multiple nodules all over body since last 5 yrs. It started initially with development of few small nodules over right forearm which gradually spread all over body involving mainly all 4 extremities, trunk, back, neck as well as few over face.

There was no history of headache, visual disturbances, cognitive impairment, seizures, of any neurological deficit. Patient was non hypertensive and non-diabetic. There was no history of TB or exposure to TB. There was no similar complaint in family members.

On examination, patient was Afebrile, with normal BP. He had multiple asymptomatic pea sized subcutaneous nodules all over body, they were well defined oval in shape with firm consistency. His cardiovascular, Respiratory, Abdominal examination was within normal limits. Neurological examination was normal. Fundus examination was normal.

During laboratory evaluation, his absolute eosinophilic count was raised which was 522 . He was HIV negative. ELISA for cysticercal antibodies was positive. His chest x-ray was normal. USG abdomen was showing multiple eccentric lesions of $0.5 \times 0.8 \mathrm{~cm}$ with hyperechoic focus within noted in subcutaneous flare all over abdomen, no intra-abdominal lesion.

His CT brain was done which was suggestive of multiple granulomatous lesions scattered throughout brain parenchyma with some showing eccentric calcified focus s/o neurocysticercosis (proto-scolex and calcified stage). There was also involvement of temporalis, masseter, bilateral posterior neck muscles and superior oblique muscles on left side.

Excisional Biopsy of nodule from forearm revealed Biloculated cyst with scolex in it and surrounding connective tissue. It was composed of bladder wall of cysticercus showing thin tegment, muscle layer and loose mesenchyme. Cyst wall was lined by fibrous tissue showing foreign body giant cells and lymphocytes. Patient was treated in a private hospital with 2 cycles of Albendazole $30 \mathrm{mg} / \mathrm{kg} /$ day with steroids for 8 days.

However there was no response. Patient was started with Tab praziquantel $(50 \mathrm{mg} / \mathrm{kg} / \mathrm{day})$ for 21 days, Tab prednisolone 20mg twice a day, also Tab phenytoin $100 \mathrm{mg}$ three times a day was started to prevent occurrence of seizures in future. At follow up 3 months later, there was marked reduction in the sizes and numbers of subcutaneous nodules and with the patient remaining seizure free. At follow up after 6months, there was complete resolution of most of cutaneous lesions and CNS lesions.

DISCUSSION: This patient has fulfilled the diagnostic criteria for human neurocysticercosis. Presence of 1 absolute criterion out of 3 is required for a definitive diagnosis as proposed by Del Bruttoetal' 5 i.e. Cystic lesions showing the scolex on CT or MRI. He also had 1 major and 1 minor criterion. His ELISA for cysticercal antibodies was positive and he had innumerable subcutaneous nodules all over body. Cysticerci can lodge themselves in any part of the ocular and extraocular tissues and associated brain parenchyma involvement is also quite rare. Our patient had cysticerci in left superior oblique muscle. A case of orbital cysticercosis associated with multiple cysts in the brain and subcutaneous tissue was reported as probably the first such case by Pushkeret al. ${ }^{11}$ 
Case of human cysticercosis with such extensive dissemination, virtually involving all possible sites viz. brain, eyes (extra ocular), muscles and subcutaneous tissues simultaneously, is indeed very rare. Though few cases are previously reported, all of them had some or the other neurological deficit. But in spite of having large number of intracranial cysticerci patient was totally asymptomatic. Albendazole resistant though is not reported yet. Response to Praziquantel following Albendazole failure is also not reported. Case is thus most unusual.

\section{REFERENCES:}

1. Kumar A. Disseminated cysticercosis in child: whole body MR diagnosis with use of parallel imaging. Pediatr Radiol 2010; 40:223-7.

2. Larry E Davis, Richard T Johnson. Neurocysticercosis. Medlink Neurology: May 2013.

3. Takayanagui OM, Odashima NS. Clinical aspects of neurocysticercosis. Parasito Int 2006; 55 Suppl: S111 - 5. Epub 2005 Dec 5.

4. Schmidt DK, Jordaan HF, Shchneider JW, Cilliers J. Cerebral and subcutaneous cysticercosis treated with albendazole. Int J Dermatol 1995; 34: 574-9.

5. Del Brutto O. H, V. Rajshekhar, A. C. White Jr, V. C. Tsang, T. E. Nash, O. M. Takayanagui. Proposed diagnostic criteria for neurocysticercosis. Neurology 2001, 57:177-183

6. Wilson M, Bryan RT, Fried JA et al. Clinical evaluation of the cysticercosis enzyme, linked immunoelectrotransfer blot in patients with neurocysticercosis. J Infect Dis. 1991; 164; 1007 1009

7. Valia RG, Valia AR. IADVL Textbook of Dermatology. $3^{\text {rd }}$ ed. Mumbai, India: Bhalani Publishing House; 2010.p. 441-4.

8. Wolff K, Goldsmith LA, Katz SI, Gilchrest BA, Paller AS, Leffell DJ. Fitzpatrick's Dermatology in General Medicine. $7^{\text {th }}$ ed. USA: The McGraw-Hill Companies Inc.; 2008.p. 2027-8.

9. Diazgranados-Sánchez JA, Barrios-Arrázola G, Costa JL, Burbano-Pabon J, Pinzón-Bedoya J. Ivermectin as a therapeutic alternative in neurocysticercosis that is resistant to conventional pharmacological treatment. Rev Neurol. 2008 Jun 1-15; 46(11):671-4.

10. Graciela Cárdenas ${ }^{1}$, Roger Carrillo-Mezo et al. Subarachnoidal Neurocysticercosis nonresponsive to cysticidal drugs: a case series. BMC Neurology 2010, 10:16.

11. Pushker N, Bajaj MS, Balasubramanya R. Disseminated cysticercosis involving orbit, brain and subcutaneous tissue. J Infect 2005; 51(5): e 245-8. 


\section{CASE REPORT}

\section{BEFORE TREATMENT:}
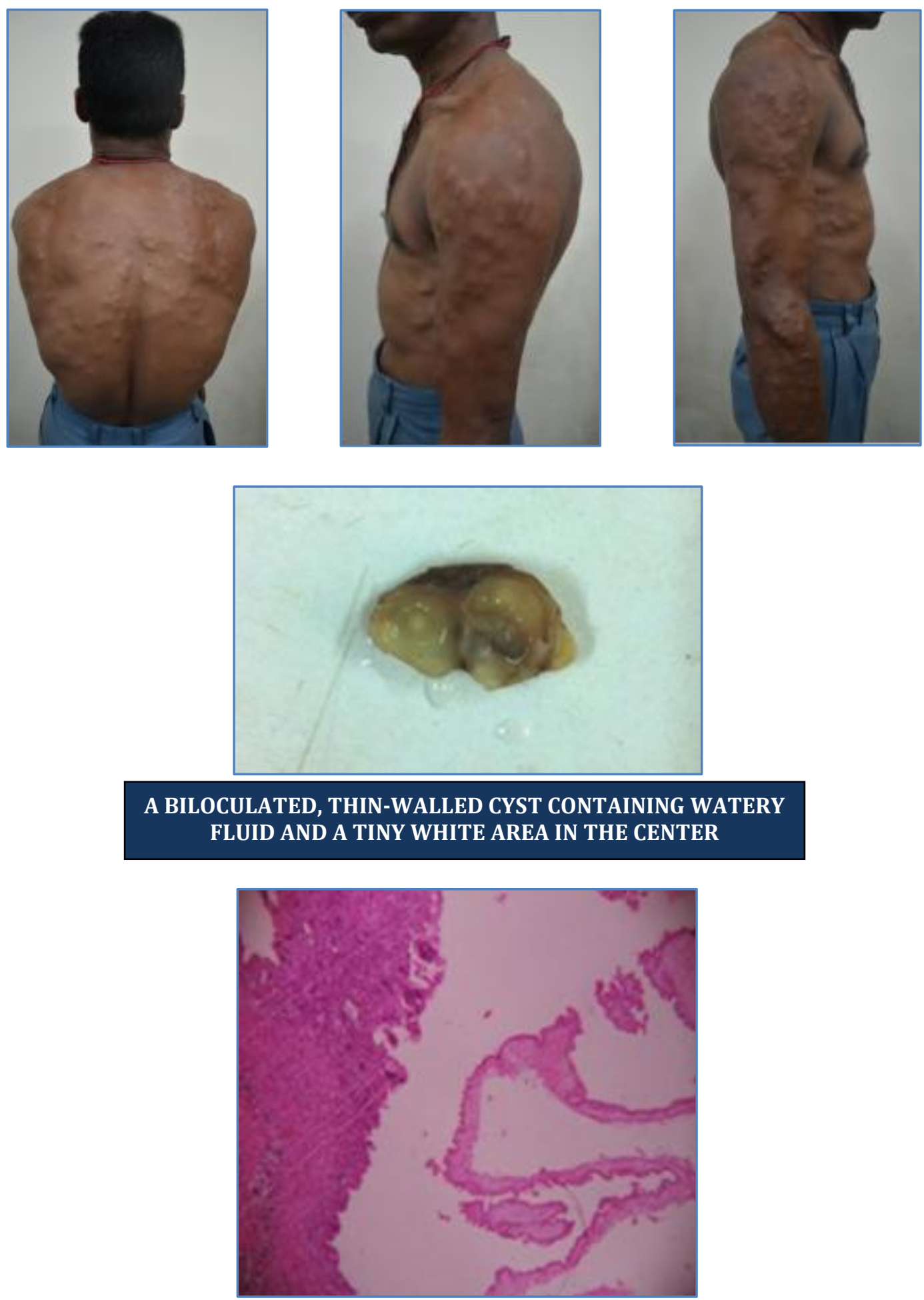

HISTOPATHOLOGY OF A SUBCUTANEOUS FOREARM NODULE, SHOWING ENCYSTED LARVA OF THE CYSTICERCUS SURROUNDED BY A CHRONIC INFLAMMATORY INFILTRATE AND GIANT-CELL REACTION (H AND E, × 100) 


\section{CASE REPORT}

\section{AFTER TREATMENT:}
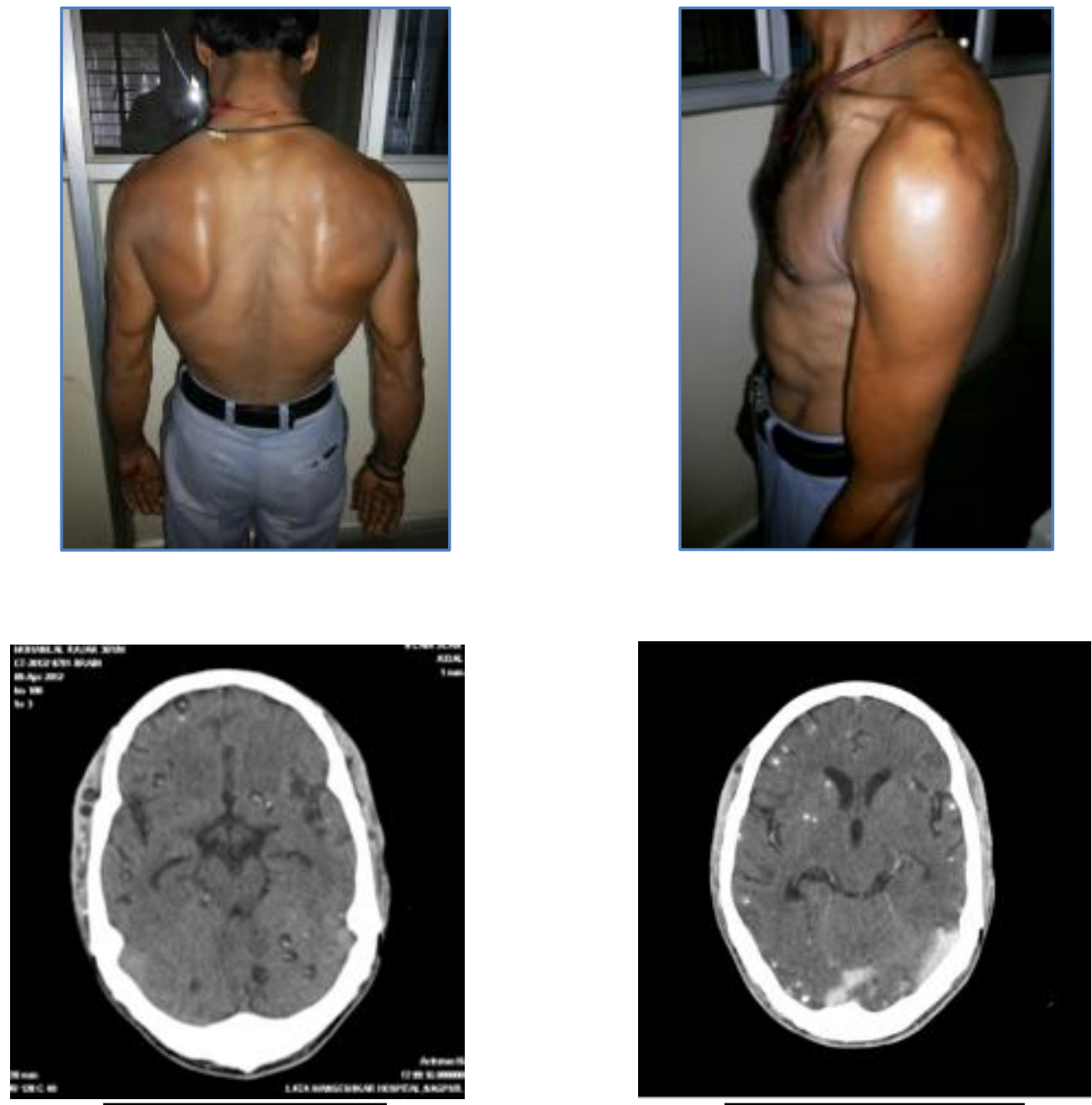

PRE-TREATMENT

\section{POST-TREATMENT}

\section{AUTHORS:}

1. Prasad Dipak Andhare

\section{PARTICULARS OF CONTRIBUTORS:}

1. Post Graduate Student, Department of General Medicine, NKP Salve Institute of Medical Sciences.

\section{NAME ADDRESS EMAIL ID OF THE} CORRESPONDING AUTHOR:

Dr. Prasad Andhare,

H.O. Hostel, Room No. 24,

NKP Salve Institute of Medical Sciences,

LMH, Hingna Road, Nagpur.

E-mail: prasadandhare7@gmail.com

Date of Submission: 01/03/2014.

Date of Peer Review: 03/03/2014.

Date of Acceptance: 11/03/2014.

Date of Publishing: 25/03/2014. 